\title{
Difficulties for cardiovascular retrospective diagnosis on mummified foetal remains
}

Received: 25 July 2012; Accepted: 31 August 2012; First published online: 27 September 2012

We read with great interest the recent article by Séguéla et al, ${ }^{1}$ which raises the problem of longterm conservation and retrospective diagnosis on foetal mummified bodies. Indeed, some incertitude exists with regard to the methods and results, needing further data from both forensic anthropology and radio-pathology points of view.

First, organs are very mobile within a mummy regardless of its archaeological or forensic origin and images of organs within their cavities can vary from one position of the body to another. ${ }^{2}$ Therefore, the right-sided position of the "heart" observed on computed tomography-scan images is not necessary the real intra-vitam one. The authors assess that "it was a primary dextrocardia rather than a simple displacement of the heart" (p. 3). What about the aorta? Is a flattening visible on the right anterior part of the lower thoracic and upper lumbar vertebras, as currently seen in that case? ${ }^{3}$ The aorta is an anatomical structured fixed to the vertebra - and subject to a much less risk of postmortem displacement, and thus it may help in confirming the diagnosis.

Second, the crushing of the skull as a consequence of a forceps extraction is not so clear. Forceps are not attested in the Egyptian antiquity, ${ }^{4}$ but existed during the Ptolemaic period (4th to 1st century BC), corresponding to the datation of these remains. ${ }^{5}$ In all cases, the use of such material for so tiny remains foetal body at 15 weeks of gestation - seems unclear. Maybe the crushing of the skull vault is merely due to post-mortem changes such as maceration of the foetus, ${ }^{6}$ or any embalming process - such as wrapping, for example).

Furthermore, the nature of the "heart" is very dubious, and this is really a limit of non-destructive methods such as post-mortem computed tomographyscan. Full-density screening - measure of Hounsfield

Correspondence to: Dr P. Charlier, MD, PhD, Department of Forensic Medicine and Pathology, University Hospital R. Poincaré (AP-HP, UVSQ), 104 R. Poincaré boulevard, F-92380 Garches, France. Tel: +33 1471076 80; Fax: +3314710 76 83; E-mail: ph_charlier@yahoo.fr
Unit for each internal structure - is the rule, and may confirm - or not? - the exact nature of the organ. What about the liver and other visceral organs? As seen in Figure 1d (p. 2), no isolate organ can be determined, but rather a homogenised entity. Does it correspond to altered organs after initial decomposition process? Or to linen packs following an embalming, as we know it was carried out even on foetuses? ${ }^{8}$ The same with the so-called "heart": "supposed cardiac structure" appears very long (extended on almost 10 thoracic vertebral bodies (unfortunately, there is no scale on the images), which is very long for a foetal heart. In addition, no ventricular and/or auricular cavity is visible. Identification of the spleen is also very dubious. The only way of being sure would be to perform an autopsy with further histological/microscopic examination, that is, a destructive method that cannot be carried out for museum reasons.

$$
\begin{array}{r}
\text { Philippe Charlier } \\
\text { Department of Forensic Medicine and Pathology, } \\
\text { University Hospital R. Poincaré (AP-HP UVSQ), } \\
\text { Garches, France }
\end{array}
$$

Department of Medical Ethics and Legal Medicine, University Paris 5, Paris, France

Isabelle Huynh-Charlier

Department of General Radiology, University Hospital Pitie-Salpetrière (AP-HP), Paris, France

\section{References}

1. Séguéla PE, Pierrat-Bonnefois G, Paul JF. A dextrocardia in a foetal Egyptian mummy? Cardiol Young 2012: 1-4.

2. Cesarani F, Martina MC, Ferraris A, et al. Whole-body three dimensional multidetector CT of 13 Egyptian mummies. Am J Roentgenol 2003; 180: 597-606.

3. Charlier P, Costea G, Huynh-Charlier I, Brun L, de la Grandmaison GL. Diagnosis of aortic dextroposition on human skeletal remains. Leg Med (Tokyo) 2012; 2: 101-104.

4. Sullivan R. Divine and rational: the reproductive health of women in ancient Egypt. Obstet Gynecol Surv 1997; 52: 635-642. 
5. Burns DN, Calache LD. An evaluation of some early obstetrical instruments. Caduceus 1987; 3: 33-40.

6. Charlier P, Khung-Savatovsky S, Huynh-Charlier I. Forensic and pathology remarks concerning the mummified fetuses of King Tutankhamun. Am J Roentgenol 2012; 198: W629.
7. Villa C, Lynnerup N. Hounsfield units ranges in CT-scans of bog bodies and mummies. Anthropol Anz 2012; 2: 127-145.

8. Hawass Z, Saleem SN. Mummified daughters of King Tutankhamun: archeologic and CT studies. Am J Roentgenol 2011; 197: W829-W836. 